\title{
UNIVERSAL PUBLIC HEALTH INSURANCE AND PRIVATE COVERAGE: EXTERNALITIES IN HEALTH CARE CONSUMPTION
}

\author{
Sherry A. Glied \\ Working Paper 13885 \\ http://www.nber.org/papers/w13885 \\ NATIONAL BUREAU OF ECONOMIC RESEARCH \\ 1050 Massachusetts Avenue \\ Cambridge, MA 02138 \\ March 2008
}

I thank Mark Stabile and participants at a seminar held by the Faculty of Law of the University of Toronto for very helpful comments. The views expressed herein are those of the author(s) and do not necessarily reflect the views of the National Bureau of Economic Research.

NBER working papers are circulated for discussion and comment purposes. They have not been peerreviewed or been subject to the review by the NBER Board of Directors that accompanies official NBER publications.

(C) 2008 by Sherry A. Glied. All rights reserved. Short sections of text, not to exceed two paragraphs, may be quoted without explicit permission provided that full credit, including $\bigcirc$ notice, is given to the source. 
Universal Public Health Insurance and Private Coverage: Externalities in Health Care Consumption Sherry A. Glied

NBER Working Paper No. 13885

March 2008

JEL No. H23,I18

\begin{abstract}
$\underline{\text { ABSTRACT }}$
Inequality in access to health care services, through private purchase, appears to pose policy challenges greater than inequality in other spheres. This paper explores how inequality in access to health care services relates to social welfare. I examine the sources of private demand for health insurance and the ramifications of this demand for health, for patterns for government spending on health care services, and for individual and social well-being. Finally, I evaluate the implications of a health tax as a response to the externalities of health service consumption, and provide a rough measure of the tax in the context of the Canadian publicly-financed health care system.
\end{abstract}

Sherry A. Glied

Mailman School of Public Health

Columbia University

Department of Health Policy and Management

600 West 168th Street, Room 610

New York, NY 10032

and NBER

sag1@ columbia.edu 
Private sources - out of pocket payments and private insurance - constitute an increasingly large share of total health care expenditures in most developed countries with predominantly public health insurance systems (Propper and Green, 1999). To an observer from outside the world of health care, there would appear to be very little novel, or worth discussion, about a delivery system that combines public and private financing. In modern economies, mixed financing of basic needs is the norm. In some cases, needs-based public financing guarantees a floor of some good (food, housing). Private funds then finance purchases for those with incomes above the need threshold. In some cases, the government provides a universally available basic allocation and actively encourages the purchase of added supplemental private coverage (retirement and disability income support). In other cases, government provides a package of services viewed as adequate by most consumers but permits those who wish to do so to purchase additional services (education, security). Why might such a mix - or a growing private share in that mix - be undesirable in the case of health care?

In this paper, I explore the possible bases of such an argument from an economic perspective. I base my analysis on the assumption that private purchases should be limited if such purchases make non-purchasers, worse-off. That is, there is an economic rationale for limiting supplementary purchases if - but only if -- such purchases generate significant negative externalities.

Framing the issue in terms of negative externalities raises a second set of questions about how government should respond to these externalities. The debate generally asks whether purchases should be permitted or prohibited. I argue that, in this context, the best response to 
any externalities is to impose taxes that lead purchasers to internalize the consequences of their purchasers. Taxation, I assert, will improve the welfare of both purchasers and nonpurchasers relative to an outright prohibition.

1. The Demand for Private Services in the Context of Public Funding

The first step in understanding how private purchases might affect non-purchasers is to consider why people might be willing to pay for (that is, demand) such services. Below, I consider two possible sources of a willingness to pay for private services in a publiclyfinanced system.

One rationale for private insurance depends on the existence of long waiting lists. Crossnational evidence suggests that some publicly-financed systems have reduced or eliminated such waiting lists (Flood, Stabile, and Kontic, 2005; Siciliani and Hurst, 2004). The elimination of waiting lists, however, is likely to be quite costly (Siciliani and Hurst, 2004; Lindsay and Feigenbaum, 1989). Moreover, a willingness to pay for supplemental purchases is endemic to publicly-financed health care systems and cannot be fully addressed simply by improving the efficiency of the public system.

\section{a. Political Economy of Public Financing}

The most straightforward reason to expect a willingness to pay for private services in a publicly-financed system is that people differ in their incomes and in their willingness to pay for health care services. Numerous studies at both the individual, regional, and national levels suggest that the income elasticity of demand for health care services is positive higher income people demand more health care services than do lower income people. Estimates of the elasticity range from 0.22 in individual analyses (Manning and Marquis, 
1996) to more than 1 in cross-national estimates (Newhouse, 1977). The positive elasticity likely reflects a willingness (and ability) to pay more for a given level of health outcomes, as well as greater demand for health, medical quality, convenience, and amenities.

Suppose people vote on the level of health care services that should be provided by the public system. The level of health spending chosen will correspond to that selected by the median voter (where median reflects level of preference for such spending). Some voters will be willing to pay for more health care services than the median and will, at the median choice, have an unmet demand for health care services (Epple and Romano, 1996). Since the income elasticity of demand for health care services is positive, these unsatisfied voters will mainly be higher income people who will be willing and able to purchase supplemental coverage to meet their excess demand.

\section{b. Extended moral hazard}

Another feature of public health insurance systems that intensifies the willingness to pay for private services is the moral hazard that arises from insurance itself. Public health insurance reduces the cost of care at the point of purchase. In Canada, for example, most publicly-provided services are free to the consumer at the point of service.

This reduction in prices at the point of service generates demand for insured services (moral hazard). The demand for services paid for by public insurance, however, is complementary to many other services. For example, the availability of free physician visits increases the demand for prescribed medications, even if those prescriptions are paid out-ofpocket rather than by any insurance plan. The availability of free hospital care increases the 
demand for private rooms and other non-covered hospital amenities. The availability of free surgical treatment increases the demand for speedy diagnostic tests that reveal the need for such surgical treatment. Thus, the moral hazard generated by the public insurance systems spills over into the private market, generating a willingness to pay for complementary services.

\section{c. Summary}

Publicly-financed health systems almost inevitably generate a willingness to pay for additional private services. This demand arises because the political system will necessarily leave some people at the extremes of the preference distribution unsatisfied. This general problem is aggravated by a prized feature of many public health insurance systems—-free or low cost care at the point of service. Together, these features generate a demand for services in a mixed private-public system that exceeds that generated by a purely public system and, in many scenarios, even exceeds that generate by a purely private system.

\section{Externalities of Private Purchase}

How should society respond to the private purchase of health services? That depends on the consequences for non-purchasers and for the system as a whole of this excess demand. I next consider three areas where externalities of private purchase might exist: health, aggregate expenditures, political and political economy.

\section{a. Health}

An obvious reason for limiting private purchases of health care by some people would be if such purchases directly made other people less healthy. Greater spending by some people 
could harm the health of others if inequality in health access generated negative biological consequences for those of lower status (Lynch et al., 2004).

Socioeconomic differentials in health are large and appear to be growing. Together with the positive income elasticity of health care demand, this implies that higher income people are both willing to pay more for health care services and are, on average, healthier than others. The contribution of access to health care services to the observed socioeconomic differentials in health is not clear. Differentials are growing in countries that have universal insurance coverage, as well as in those that do not. Yet it seems plausible that using more or better medical care does play some part in the differential. Concerns about the equity implications of differential access rest in large part on the existence of some meaningful connection between health care services and well-being. If there were no such connection, it would be hard to see why public policy should prohibit people from wasting their money on useless consumption of private services.

Differential financial access to health care services may intensify the existing variation in health status between higher income and lower income people. The difference would occur as higher income people became healthier faster than lower income people did. This increase in inequality, however, would not directly make lower income people worse off.

Some epidemiologists have gone further and argued that inequality (in income) itself relative poverty -- might directly generate a diminution in the health of lower income groups, holding constant the income of these individuals themselves (Health Canada, 1999). Thus, this literature asks the same question in the context of health as I am asking in the context of health care services: holding resources for lower income groups constant, does an increase in the resources available to higher income groups make lower income people worse off? 
A substantial literature points to an empirical correlation between income inequality and average health across nations. Holding average income constant, countries with more equal income distributions do have better average health outcomes. The implication of this crosssectional finding, however, is unclear. Studies that examine changes in income inequality within a country over time find that these do not generate corresponding changes in health outcomes (even considering lagged effects). Rather, those countries that have historically had more equal distributions of income are also countries that have tended to have better health. The correlation between income inequality and health at the aggregate level appears to be an artifact of aggregation. The most recent comprehensive review of the literature entirely rejects the proposition that relative income affects health in developed countries (Lynch et al., 2004).

Income is a substantial determinant of health in its own right and can be a factor in generating unequal access to health services. But the literature on relative income and health suggests that increasing the incomes of the richest does not directly harm the health of lower income groups ${ }^{1}$. To be sure, none of this literature directly examines whether increasing health access for the richest, while holding access constant for all others, harms the health of lower income groups. Still, the literature generally rejects the proposition that private access to additional health services will generate negative health consequences for low income people through relative deprivation. Thus, there is no evidence of a direct externality of private health care consumption on health.

\footnotetext{
${ }^{1}$ Increases in the incomes of rich people may induce additional investment in technologies that treat illnesses affecting higher income groups. Eventually, the benefits of these technological investments may "trickle down" to other groups. It is theoretically unclear, however, whether this acceleration in technological development is socially optimal (see Baumgardner, 1991) and empirically unclear whether these "trickle down” benefits occur (Meara, Richards, and Cutler 2005; Glied and Lleras-Muney, 2003).
} 


\section{b. Expenditures/Availability of Services}

A second possible source of externalities is through effects of private spending on aggregate public expenditures - or, if spending does not adjust, on the level of services available in the public sector. In evaluating the possible existence of such externalities, it should not be assumed that the existing level of public expenditures or the level of services is optimal. Increased private spending might lead to a warranted increase or decrease in public spending.

Alternatively, if aggregate public spending is not permitted to increase (or decrease), any externalities generated through private spending will take effect on the quantity side of the public sector, reducing (or increasing) the availability of services for those who hold only public insurance. The most direct way in which this change in availability is likely to occur is through a change in waiting times in the public system (as in Olivella, 2002).

\section{i. Voting/Optimal Provision}

The public choice model of public provision of private goods (Epple and Romano, 1996) suggests that allowing supplemental private purchase will generally lead to a reduction in public expenditures. The logic of this argument is that under a system that permits private purchase, higher income voters will prefer a lower level of public health care spending than otherwise, choosing to top up public spending with private purchases. Permitting private purchase will move the winning median voter down the distribution of health care service demand.

The empirical evidence on private spending is consistent with this theoretical result. Tuohy, Flood, and Stabile (2004) find that the existence of private insurance tends to lead to future reductions in public spending in analyses across the OECD.

A further implication of reduced public spending when private provision is permitted is that systems with mixed public and private payment will spend more on health care services (in 
aggregate) than will purely publicly-funded systems. Average (mean) income is generally higher (often much higher) than median income. This pattern suggests that under private supplemental purchase, the willingness to pay for private services, which depends on the average income of the population, will rise faster than the demand for public services (which depends on the income of the median voter) will fall. Epple and Romano (1996) further show that if the willingness to pay for a good increases with an increase in income faster than with a decline in prices (as is likely the case in health care, see Manning and Marquis, 1996), purely public systems will spend less than either mixed or purely private health care systems.

This increase in overall spending and reduction in public spending generally increases overall social welfare in voting models. Both private purchasers and some public purchasers those with low willingness to pay for health care services - are better off in the scenario where some private purchase is permitted ${ }^{2}$. Public purchasers with low willingness to pay for health care will benefit as services are reduced and either taxes fall or social spending is diverted to programs they value more highly.

Models in which social planners choose the length of waiting times to maximize social welfare likewise generate the result that the optimal length of waiting lists in the public sector is generally greater if private services are available than if they are not (Olivella, 2002; Allard, Jarry, and Leger, 2007; Iversen, 1996) .

\footnotetext{
${ }^{2}$ This argument should not be taken to imply that public provision of private goods is always welfare reducing. Public provision can improve welfare in situations of informational asymmetry. For example, redistribution of a limited amount of child care through in-kind transfers may lead to lower distortions than would occur if redistribution took the form of cash assistance. The in-kind transfer leads high and low ability people to self-select and reveal their endowments (Blomquist and Christiansen, 1999; Nichols and Zeckhauser, 1982). Similarly, universal public insurance can overcome adverse selection problems and generate efficiency gains.

${ }^{3}$ The general welfare consequences of permitting private insurance (rather than prohibiting it) vary depending on the organization of coverage and the parameters of these models.
} 


\section{ii. Monopsony}

Single payer health insurance systems can exploit their monopsony power to keep prices low. Permitting the private purchase of services breaks up the monopsony and necessarily limits the ability of public price setters to keep prices down.

This reduction in monopsony power may manifest itself in several ways. Providers may negotiate more aggressively for higher rates when they have an alternative source of payment. They may shift service provision to the private sector, reducing the availability of services to patients in the public sector (Iversen, 1996; Morga and Xavier, 2001). The general result will be that patients in the public sector will either receive fewer services (if spending is fixed) or have to pay more for the services they receive (if service levels are fixed). In either case, taxpayers will be worse off because of the reduction in monopsony power.

This pattern is exacerbated by provider agency. In health care markets providers have more information than do consumers. Consumers - patients - rely on providers to direct them to appropriate treatment and to guide their care. In a situation where the public insurer regulates prices below the level paid in the private market, providers who work in both the private and public sectors have an incentive to shift demand toward the private sector. In this scenario, providers will respond to the difference between monopsony prices and private prices by reducing their hours or level of service in the public sector, in favor of demand in the private sector (Iversen, 1996; Morga and Xavier, 2001).

Whether the effect of private purchase on the supply of services to the public sector operates through prices or through quantities depends on the response of the public sector to competition in demand. One alternative, used by the United States Medicare program and by most others, is to continually adjust (raise) prices paid by the public sector so that a substantial 
percentage of providers continue to participate in the public program. In an effort to reduce the effect of private purchase on prices paid in the public sector, many health care systems also require providers to choose whether to opt-into the public program. Those who choose to opt-in may not accept private pay patients at all or may only accept private patients after they have supplied a pre-specified level of effort to the public program.

An increase in expenditures through the elimination of monopsony power is generally viewed as welfare-improving. Prices rise but overall use of services increases. Moreover, providers gain and their gains also figure into calculations of social welfare.

The analysis of welfare implications is complicated somewhat in the case of health care. Monopsony power reduces the cost of achieving some level of redistribution. A decline in monospony power means that a greater level of distortionary taxes will be needed to achieve the same level of redistribution. Holding the level of redistribution constant, allowing private purchases makes those who use additional services and health care providers better off, but makes taxpayers worse off.

If the supply of services is completely insensitive to price (inelastic), the introduction of private insurance will drive up prices paid by the public sector (or reduce quantities purchased in that sector) without any offsetting increase in aggregate quantity. In this situation, private purchase of services simply transfers funds from consumers to providers, redistributing scarce services among consumers, but with no implications for aggregate welfare. This situation is, however, unlikely. At the individual level, providers can increase their hours of work or delay retirement in response to increased marginal prices. In aggregate, existing providers can invest in training to develop more highly compensated skills, changes can be made in existing 
processes of care to alter the skill mix needed for provision of specific medical services, and providers (particularly physicians) can immigrate from abroad.

I now consider three scenarios under which public expenditures would rise in the presence of private purchase, and the general welfare consequences are unambiguously negative. In these scenarios, private purchasers may be made better or worse off, but non-purchasers are generally worse off because they are spending more for the same services (or receiving fewer services - facing longer waiting lists -- for the same level of spending).

\section{iii. Insurance for Complementary Services}

Private spending may take several forms. One common form of private spending in a publicly funded system is through the purchase of insurance that covers services complementary to those provided in the public system, such as pharmaceuticals.

This insurance for services complementary to the public system generates moral hazard in the purchase of services it covers. People with pharmaceutical coverage, for example, buy more drugs, whether pharmaceutical coverage is privately or publicly financed. If the insured services are complementary to services covered by the public health insurance system, the private insurance also generates moral hazard in the public system. Controlling for health status and other characteristics, for example, people with pharmaceutical coverage in Canada use about 5\% more physician visits than do those without such coverage (Stabile, 2001). In the U.S. Medicare system, supplemental "Medigap” coverage covers coinsurance for services obtained in the public system. Controlling for selection into coverage, people with Medigap coverage have public expenditures that are about $6 \%$ higher than do those without such private coverage (Atherly, 2002). 
Additional use of public services generated through such complementary private insurance unambiguously reduces social welfare. Moreover, this increase in public spending is not captured in the premium on the private insurance policies themselves. Instead, the increase in public spending constitutes a negative fiscal externality imposed on taxpayers who fund the public system (or to those without such coverage who now receive fewer publicly funded services).

iv. Private Purchases of Substitute Services

A second form of private purchase is direct purchase of services - often high technology diagnostic testing services -- also offered in the public plan (using out-of-pocket payments, not insurance). Private purchase of such services is often prompted by long waiting lists or insufficiently prompt or friendly access for publicly provided services. These services are directly complementary to treatment services available in the public insurance system. Waiting lists for access to these up-front services have the effect of acting as a gatekeeping device, rationing access to downstream treatment services (which may not exhibit waiting lists).

In these contexts, private purchases enable people to substitute a price rationing mechanism - direct payment - for a non-price rationing system (waiting lists or inconvenience). People are willing to pay extra to move to the front of a queue or get additional physician attention because obtaining a service immediately or conveniently increases the value of the service (Lindsay and Feigenbaum, 1984). The extra value of these services means that willingness to pay for them will increase when price rationing substitutes for waiting list rationing. People will not only obtain diagnostic tests faster when they can obtain them right away. They will also use more such services. 
Moreover, the incentive to purchase diagnostic testing is itself increased by the presence of publicly-insured complementary services. Increased use of diagnostic testing, in turn, will generate an increased demand for complementary publicly-provided services. In medical care, complementaries abound (and substitutes are hard to find). More and earlier diagnosis of disease will, almost inevitably, mean more treatment of disease and greater aggregate expenditures. The increase in use of publicly-funded services induced by overriding gatekeeper rationing raises public expenditures and reduces welfare. Here, too, private purchases impose a negative externality on taxpayers (or on non-purchasers of complementary services).

\section{v. Full Replacement}

A final model of private purchase is one in which people buy private insurance in lieu of participating in the public health insurance system, as in Germany and the Netherlands. In these cases, private insurance purchasers neither obtain public coverage nor pay premiums toward it (Den Exter, 2005; Greß, 2005). A somewhat similar situation exists in the purchase of HMO coverage among U.S. Medicare beneficiaries, where beneficiaries pay the same taxes but opt out of the traditional fee-for-service program. By design, these programs, operating entirely outside the public health care system, do not generate moral hazard within that system. They may, nonetheless generate fiscal externalities to that system.

The principal problem in the case of full replacement insurance is that healthier people are more likely to participate in private coverage than are similar people with health problems. If private insurers may vary premiums to reflect health status, sicker people will be better off remaining in the public system. If private insurers cannot vary premiums, they are likely to design their benefits in ways that "cream skim” -- attracting healthy people and deterring sicker 
ones from joining. They can do this in many ways, including offering supplementary benefits that attract healthy buyers (discounted gym membership), or limiting benefits attractive to unhealthy buyers (including few oncologists on a provider panel).

Studies of full replacement private insurance systems frequently find evidence of such favorable selection by private insurers (Greß, 2005). In the case of US Medicare, for example, studies found that HMO purchasers were between 6-70\% healthier, on average, than were those who remained in the traditional fee-for-service system (Mello et al., 2003).

The distortions in benefit design that stem from the desire to select healthier buyers are themselves welfare reducing. Moreover, when private insurers attract healthier than average people, this can often increase deficits in the public system. Selection also reduces revenues in systems where private purchasers are exempted from progressive (e.g., payroll tax) financing (Greß, 2005). Private coverage will tend to appeal most to those who paid the highest premiums (through payroll taxes) for public insurance, and who, because they are healthy, will face low premiums for private insurance. The departure of this group from the public insurance pool will reduce revenues more than proportionally while decreasing costs less than proportionally. Again, the existence of private purchases will leave taxpayers, including non-purchasers, financially worse off (or obtaining fewer services for the same funds).

\section{c. Well-being}

Even if private purchases of services do not lead to increased per capita expenditures in the public sector, they might still make non-purchasers worse off through their effects on satisfaction with the health care system at any given level of purchasing. Here, externalities occur when the consumption of services by one person enters the utility function of another (Rice, 1998). Although there is no a prior reason that such interdependencies should occur more 
in health care than in other arenas, the existence of universal health insurance programs (and the absence of universal housing, income, or food programs) suggests that this arena may be one in which we seek to "limit the domain of inequality" (Tobin, 1970).

i. Envy, Snob Effects, and Expectation Formation

Utility-based arguments about externalities depend critically on the form of interdependencies in welfare. The form of such interdependencies is not at all obvious. For example, it is possible that people who do not purchase private services would be envious of the purchases of others and this would make them unhappy. On the other hand, private purchases might equally generate pretentiousness or snob effects, where private purchasers were tickled by their purchases simply because others could not afford them (Dowd, 1999).

Private purchases could affect well-being even without envy if they change people’s expectations about what constitutes appropriate service. For example, people may be satisfied with receiving services within a "reasonable" amount of time. The perceptions of what constitutes a reasonable amount of time, however, are likely to depend on typical practice. If private purchasers are able to obtain services more rapidly, public purchasers may begin to view current service delivery patterns as unreasonable.

As one of the first American health economics textbooks put it in 1961:

When Americans speak of 'adequate medical care,' they do not have in mind any finite or defined quantity or quality. The very concept is in a continuous state of flux with what is being achieved and is generally thought to be available. (Somers and Somers 1961).

Some evidence of this proposition comes from analyses of the Commonwealth Fund survey of patients with health problems in six countries (Schoen et al., 2005). In the countries where private insurance for publicly provided services is available (Australia, New Zealand, UK, and Germany), people with private insurance had shorter waits for surgical and specialist 
services, but not for general practitioner appointments or in emergency rooms (services which are not paid by private insurance). In each of these countries, people who waited longer for each of these services expressed lower levels of satisfaction with the overall health care system. Across countries, however, dissatisfaction with a given level of waiting time was lower the longer the average waiting time in the system.

In a world where expectations of service are established by the observed average, bringing down the average will increase expectations. This may affect well-being directly. It may also change the choice of public spending levels. If the median voter is a non-purchaser of private insurance, this increase in expectations will induce a demand for increased spending in the public sector. In this case, private purchases induce a fiscal externality through changes in perceptions of adequacy.

\section{ii. Equality}

Private purchases can introduce a second type of well-being externality if most people place some value on the degree of equality in the delivery of health care services. A preference for some degree of equality means more than a belief that everyone should have access to some health care (Lindsay, 1969; Pauly 1971). It also implies that the distance between the health care available to rich and poor should be held to some maximum, even when the care available to rich people improves. Policy choices in the US, where care is certainly not equally provided, suggest that public preferences do fit this model (Glied, 1997).

If equality is a value, increases in the amount of health care used by private purchasers must lead to a compensating increase in the public care available to those who cannot afford these purchases. The market will not naturally generate such increases because equality is a public good, one which we can all benefit from, even if we do not all pay to make it happen. 
Equality may be a value universally held, but each individual has an incentive to free-ride on the public provision of equality - through increased subsidies or reduced consumption -- by others (Lindsay, 1969).

\section{d. Summary}

Private purchases of care in a publicly-funded system are likely to have some direct and indirect effects on non-purchasers. Private purchasers will probably not make non-purchasers less healthy than they would otherwise be. They are likely to raise the prices paid by public purchasers, though this is not necessarily welfare-diminishing overall (and might even lead to improved efficiency in the public system).

Most institutional configurations of private purchasing - supplemental insurance, direct purchases of rationed services, and substitute private insurance - will generate fiscal externalities on the public system. In the first two cases, these externalities arise because private purchases compound the moral hazard effects inherent in the public insurance system. In the case of substitute purchases, adverse selection means that per capita expenditures will rise in the presence of private insurance. If substitute purchasers can also opt out of a progressive financing scheme, per capita revenues will drop in the presence of private insurance.

Private purchases may affect people’s satisfaction with the public system and, indirectly, the costs of that system, if expectations of adequacy depend on a comparison of an individual's experience and average experience. Finally, private purchases will undoubtedly diminish the level of equality in health care delivery. If equality of health care delivery is a widely-shared value, private purchasers will reduce this aspect of satisfaction among both purchasers and nonpurchasers 


\section{Response to Externalities}

The existence of fiscal and well-being externalities associated with private purchase suggests that social welfare may be improved by limiting or controlling such purchases. In an externality framework, the goal of such controls or limits should be to induce purchasers to internalize the external consequences of their purchases.

\section{a. Fiscal Externalities}

Whatever the legal or ethical desirability of permitting private purchases, there is little economic justification for permitting private purchasers to impose direct fiscal externalities on the public system through moral hazard or adverse selection effects. Theory and evidence suggest that existing private purchases impose such fiscal externalities. These externalities would be exacerbated should private insurance for complementary or partial substitute services be permitted.

Internalizing fiscal externalities associated with private purchases can be achieved by requiring private purchasers to compensate the public system for the costs they impose. In most cases, the simplest way to do this is to impose a tax of appropriate magnitude on such purchases.

Empirical evidence can be used to estimate the necessary magnitude of the tax in each case. Here, I illustrate this point in the Canadian context. Stabile (2001) suggests that supplementary insurance for pharmaceuticals in Canada increases the demand for physician visits by 5\%. Per capita expenditures for physician visits are about \$525 (Canadian Institute for Health Information, 2006). A tax of 5\% of this expenditure would come to about $\$ 25$ per private purchaser of this type of supplemental coverage.

Anderson et al. (2005) estimate that waiting list services account for about 3\% of per capita health expenditures, or about $\$ 125$. This figure is not quite the same as the savings in 
public system use achieved through waiting list rationing of diagnostic and related services. The complementary public services may, themselves, not be rationed and therefore should not be included in this estimate. Moreover, even in countries with both waiting lists and private insurance, most people obtain rationed diagnostic and related services in the public sector. Thus, a tax of \$125 on insurance to cover rationed diagnostic and related services would likely exceed the level needed to compensate for the externality generated through use of public services.

In the case of full replacement coverage, the tax requires both a cost and revenue component. The cost component would equal the difference between the individual's expected costs of public coverage and the average cost of public coverage. In the case of the U.S. Medicare program, a tax on HMO coverage calculated in this way would have assessed an average tax of about $10 \%$, or about $\$ 400$ per policy. Compensation for lost tax revenue would depend on the degree of progressivity in public health insurance financing ${ }^{4}$.

\section{b. Well-Being and Equality Externalities}

It is not as obvious how to address the consequences of private spending associated with perceptions of well-being or with striving to maintain some degree of equality. If relative allocations matter, the amount of redistribution needed increases as better off people spend more. Subsidizing ever-increasing amounts of redistribution becomes increasingly costly, especially when taxes are distortionary (Lindsay, 1969; Glied, 1997).

The least cost means of achieving some degree of equality, where this is a public policy goal, is to combine subsidies for lower income people with limitations on the quantity of goods and services available to higher income people (Lindsay, 1969). Subsidies impose costs through

\footnotetext{
${ }^{4}$ An alternative model to address both of these problems would raise general tax revenue to finance risk-adjusted health insurance vouchers that could be used to pay for either public or (with supplementary payment) private insurance coverage (Pauly et al, 1992).
} 
taxation and redistribution. Constraints on private purchase impose costs through the foregone consumer surplus from services not obtained. Optimal policy balances these two costs at the margin.

Spending by those with greater demand can be constrained through either prohibitions or taxation. This form of limit maintains equality in health care service delivery by keeping the top of the distribution down. The production of equality benefits those who value this feature, and harms those who would prefer to purchase private services. Prohibitions, however, do not directly improve the well-being of non-purchasers. Moreover, those who would otherwise have purchased health care retain the income they would otherwise have spent. To the extent that they spend these funds on services complementary to health care (gym memberships, for example), the limitation on health care spending will not diminish the degree of socioeconomic inequality in health either.

An alternative way to constrain health spending in this situation is to use the same externality logic as in the fiscal externality case and impose a tax on private spending, which may then be used to help finance the public system (Glied, 1997). A tax serves several simultaneous functions in this context. It increases the price of private health care services and reduces demand for them, preserving a degree of equality. It permits private purchasers who place an extremely high value on health care services to continue purchasing them. It draws money away from private purchasers, reducing the transfer of inequality to complementary services. Finally, it generates revenues that can be used to increase health resources available to non-purchasers, without requiring new distortionary taxes.

An absolute prohibition on private purchases translates into a tax rate of infinity. This rate seems difficult to justify. Our economy generates very large variations in incomes and 
tolerates equally substantial variations in the consumption of most goods and services. We accept these variations, although they often include meaningful differences in the consumption of goods and services that have large, direct impacts on health (education, safer automobiles or housing, for example). Our tolerance for inequality in so many other spheres weakens the argument that we should entirely prohibit private purchases of health services on grounds of inequality alone.

How large would the tax need to be? That depends on the extent of inequality in health care consumption viewed as acceptable and on assumptions about rates of participation in the private sector and the rate of growth of private and public spending. Under generous assumptions about participation and private spending growth, for example, a tax rate of 30\% would ensure that for the next 20 years, average spending by private purchasers was never more than $30 \%$ higher than average spending by non-purchasers. A tax to compensate for externalities of well-being or inequality would supplement any taxes needed to adjust for fiscal externalities generated through the consumption of private services. Since well-being and inequality effects are generated as readily through direct purchases as through insured purchases, the tax would be levied on private purchases however financed.

\section{Conclusions and Implications}

The question of private health care in publicly-financed systems is fraught with talk of ethics and justice. Economic analysis takes a different tack. Economics admits that private purchases may be problematic in several ways. It reframes the public policy question, however, from one of whether or not to prohibit such purchases at all to one of just how and why purchases are problematic. 
The results of this analysis suggest first, that private purchase does not have a direct impact on the health of non-purchasers. Private purchases, do, however, have significant, though relatively small, fiscal implications for the public insurance system. These fiscal implications have not been addressed in most public health insurance systems to date. Private insurance, depending on its design, might exacerbate these fiscal externalities.

Private purchases may also change people’s perceptions about the adequacy of the public system, generating increased demand for public services. They may reduce social welfare if people value the degree of equality in itself. Again, these effects are the consequence of private purchase, whether or not insurance is permitted. I do not have a precise measure of the empirical magnitude of these effects, but most components appear to be relatively small. 


\section{References}

Allard, M, Jarry, M and Leger, PT. (2007) A Model of Public and Private Care in the Presence of Private Insurance. Mimeo Institute of Applied Economics, HE Montreal.

Anderson, G.F., Hussey, P.S., Frogner, B.K., \& Waters, H.R. (2005) Health spending in the United States and the rest of the industrialized world. Health Affairs. 24(4): 903-914.

Atherly, A. (2002). The effect of medicare supplemental insurance on medicare expenditures. International Journal of Health Care Finance and Economics, 2(2), 137-162.

Baumgardner, J.R. (1991). The Interaction between Forms of Insurance Contract and Types of Technical Change in Medical Care. The RAND Journal of Economics, Vol. 22, No. 1 (Spring), pp. 36-53

Blomquist, S., \& Christiansen, V. (1999). The political economy of publicly provided private goods. Journal of Public Economics, 73(1), 31-54.

Canadian Institute for Health Information (2005). National Health Expenditures Trends, 19752004. secure.cihi.ca/cihiweb/ dispPage.jsp?cw_page=AR31_2004sum_e (downloaded, January 16, 2006).

Den Exter, A. (2005) Blending private and social health insurance in the Netherlands: Challenges posed by the EU in Access to care, access to justice: The legal debate over private health insurance in Canada. (ed. Flood, C. M., Sossin, L. \& Roach, K.). Toronto: University of Toronto Press.

Dowd, B. (1999) An unusual view of health economics. Health Affairs, 18(1), 266-269.

Epple, D., \& Romano, R. E. (1996). Public provision of private goods. Journal of Political Economy, 104(1), 57-84.

Flood, CM, Stabile, M, \& Kontic, C (2005). Finding health policy 'arbitrary”: The evidence ono waiting, dying, and two-tier systems in Access to care, access to justice: The legal debate over private health insurance in Canada. (ed. Flood, C. M., Sossin, L. \& Roach, K.). Toronto: University of Toronto Press.

Glied, S. (1997). Chronic condition: Why health reform fails. Cambridge and London: Harvard University Press.

Glied, Sherry A. and Lleras-Muney, Adriana, (2003) "Health Inequality, Education and Medical Innovation" (June). NBER Working Paper No. W9738

Greß , S. (2005) The role of private health insurance in social health insurance countries implications for Canada in Access to care, access to justice: The legal debate over private 
health insurance in Canada. (ed. Flood, C. M., Sossin, L. \& Roach, K.). Toronto: University of Toronto Press.

Health Canada. (1999). Toward a Healthy Future: Second Report on the Health of Canadians. Ottawa: Minister of Public Works and Government Services Canada.

Iversen, T. (1997). "The Effect of a Private Sector on the Waiting Time in a National Health Service." Journal of Health Economics 16: 381-396.

Johnson, D. B., \& Pauly, M. V. (1969). Excess burden and the voluntary theory of public finance. Economica, N.S., 36(143), 269-276.

Lindsay, C. M. (1969). Medical care and the economics of sharing. Economica, N.S., 36(144), 351-362.

Lindsay, C. M., \& Feigenbaum, B. (1984). Rationing by waiting lists. American Economic Review, 74(3), 404-417.

Lynch, J Davey Smith, G., Harper, S., Hillemeier, M., Ross, N., Kaplan, G.A. \& Wolfson, M. (2004). Is income inequality a determinant of population health? Part 1. A systematic review. The Milbank Quarterly 82:1, 5-99.

Manning, W. G., \& Marquis, M. S. (1996). Health insurance: The tradeoff between risk pooling and moral hazard. Journal of Health Economics, 15(5), 609-639.

Meara, E., Richards, S. and Cutler, D. (2005). "Growth in mortality and life-expectancy disparities by education 1982-2000,” Working Paper. Department of Economics, Harvard University.

Mello, M. M. (2003). Understanding biased selection in medicare HMOs. Health Services Research, 38(3), 961-992.

Morga, A. and Xavier, A. (2001). "Hospital Specialists' Private Practice and its Impact on the Number of NHS Patients Treated and on the Delay for Elective Surgery.” University of York Discussion Paper. 01/01.

Newhouse, J. P. (1977). Medical-care expenditure: A cross-national survey. Journal of Human Resources, 12(1), 115-125.

Nichols, A. L., \& Zeckhauser, R. J. (1982). Targeting transfers through restrictions on recipients. American Economic Review, 72(2), 372-377.

Olivella, P. (2002). Shifting Public Health Sector Waiting Lists to the Private Sector. European Journal of Political Economy. 19: 103-132.

Pauly, M.V. (1971). Medical care at public expense. New York: Praeger. 
Pauly, M.V., Danzon, P., Feldstein, PJ, \& Hoff, J. (1992). Responsible national health insurance. Washington, D.C.: AEI Press. .

Propper, C. \& Green, K. (1999). .A larger role for the private sector in health care? A review of the arguments.. Centre for Market and Public Organisation (CMPO), Working Paper Series No. 99/009.

Rice, T.H. (1998) The economics of health reconsidered. Chicago Ill: Health Administration Press.

Schoen, C.. Osborn, R., Huynh, P.T., Doty, M., Zapert, K., Peugh, J. \& Davis, K. (2005) Taking the pulse of health care systems: Experiences of patients with health problems in six countries. Health Affairs Web Exclusive, November 3.

Somers, H.M. \& Somers, A.R. (1961). Doctors, patients, and health insurance. Washington, D.C.: Brookings Institution.

Stabile, M. (2001). Private insurance subsidies and public health care markets: Evidence from Canada. Canadian Journal of Economics, 34(4), 921-942.

Tobin, J. (1970). On Limiting the Domain of Inequality. Journal of Law and Economics, Vol. 13, No. 2 (Oct.), pp. 263-277

Tuohy, C. H., Flood, C. M., \& Stabile, M. (2004). How does private finance affect public health care systems? marshaling the evidence from OECD nations. Journal of Health Politics, Policy and Law, 29(3), 359-396. 